\title{
Mempertahankan Desa Belega Sebagai Sentra Pengrajin Bambu
}

\author{
Ni Putu Sri Mariyatni ${ }^{*}$, Ni Made Rai Juniariani², Agus Darma Yoga Pratama ${ }^{3}$ iD \\ 1,2 Fakultas Ekonomi dan Bisnis, Universitas Warmadewa, Denpasar, Indonesia \\ ${ }^{3}$ Fakultas Sastra, Universitas Warmadewa, Denpasar, Indonesia \\ *Corresponding author: srimariyatni17@gmail.com
}

\begin{abstract}
Kabupaten Gianyar khususnya di Desa Belega, Kecamatan Blahbatuh, sebagai sentra penghasil kerajinan dari bambu, merupakan ciri khas dari desa ini, sehingga mendapat julukan Desa Bambu. Salah satu pengerajin bambu yang berasal dari desa tersebut adalah Bapak I Nyoman Sudiarta dengan spesifikasi produk adalah furniture seperti set kursi, roomdivider (sekat ruangan), hanger dan bale bambu. Terdapat beberapa permasalahan terkait dengan pengelolaan manajemen usaha dari usaha yang ditekuni dari tahun 2000an tersebut, yaitu belum melakukan pencatatan keuangan, belum memiliki sistem promosi untuk memasarkan produknya dan banyak peralatan produksi yang kondisinya sudah rusak. Jenis kegiatan yang dilakukan untuk membantu pengerajin adalah memberikan pelatihan dan pendampingan pencatatan keuangan sederhana dan pemasaran serta pengadaan beberapa peralatan baru. Tujuan dari kegiatan pengabdian ini adalah meningkatkan pemahaman mitra terkait pencatatan keuangan usaha dan pemasaran, serta meningkatkan kapasitas produksi usahanya. Hasil dari kegiatan ini adalah terdapat peningkatan aset, omset usaha, jumlah produksi serta peningkatan jumlah tenaga kerja.
\end{abstract}

Keywords: Bambu, Kerajinan, Pendampingan

\section{Abstract}

Gianyar Regency, especially in Belega Village, Blahbatuh District, as a center for producing handicrafts from bamboo, is a characteristic of this village, earning it the nickname Bamboo Village. One of the bamboo craftsmen from the village is Mr. I Nyoman Sudiarta with product specifications such as furniture such as chair sets, room dividers, hangers and bamboo bales. There are several problems related to the management of the business management of the business that he engaged in from the 2000s, namely not keeping financial records, not having a promotion system to market their products and many production equipment which are in damaged condition. The types of activities carried out to assist craftsmen include providing training and assistance in simple financial recording and marketing and procurement of several new equipment. The purpose of this service activity is to increase the understanding of partners regarding business and marketing financial records, as well as to increase the production capacity of their businesses. The result of this activity is an increase in assets, business turnover, total production and an increase in the quantity of labor

Keywords: Bamboo, Crafts, Assistance

\section{Introduction}

Bambu merupakan bahan baku ramah lingkungan yang dapat di buat beraneka ragam jenis barang kerajinan. Bambu merupakan salah satu tumbuhan yang penting bagi kehidupan masyarakat di pedesaan (Linda et al., 2017; Rahmawati et al., 2019). Bambu bersifat kosmopolit yaitu dapat bertahan hidup dalam segala cuaca, baik di daerah panas maupun dingin, di dataran rendah, tebing maupun di pegunungan (Arsad, 2015). Bambu memiliki sifat dasar kayu dan bukan kayu karena bisa digunakan untuk konstruksi rumah, jembatan, barang kerajinan, bahan penghara industri alat musik, tirai, peralatan dapur, sumpit dan lain

$\begin{array}{ll}\text { History: } & \\ \text { Received } & : \text { 2 Juni } 2020 \\ \text { Revised } & : \text { 11 Juli } 2020 \\ \text { Accepted } & : \text { 20 Juli } 2020 \\ \text { Published } & : 01 \text { Agustus } 2020\end{array}$

Publisher: Undiksha Press

Licensed: This work is licensed under

a Creative Commons Attribution 3.0 License

Published : 01 Agustus 2020 
sebagainya. Bambu merupakan salah satu jenis rumput-rumputan yang termasuk ke dalam famili Gramineae dan merupakan bagian dari komoditas hasil hutan bukan kayu (Saputra et al., 2019; Tang et al., 2019). Bambu merupakan salah satu hasil hutan non kayu yang banyak tumbuh di hutan sekunder dan hutan terbuka, walaupun ada diantaranya yang tumbuh di hutan primer (Adhany \& Siregar, 2020; Sulistiono et al., 2016). Tumbuhan ini banyak dimanfaatkan oleh masyarakat baik di pedesaan maupun perkotaan secara intensif.

Bambu merupakan tanaman yang sangat bermanfaat bagi kehidupan ekonomi masyarakat (Putro \& Murningsih, 2014; Raka et al., 2011). Sampai saat ini bambu sudah dimanfaatkan sangat luas, mulai dari penggunaan teknologi yang paling sederhana sampai pemanfaatan teknologi tingi pada skala industri. Pemanfaatan di masyarakat umumnya untuk kebutuhan rumah tangga dengan teknologi sederhana, sedangkan untuk industri biasanya untuk orientasi ekspor (Arhamsyah, 2009). Jadi, bambu memegang peranan sangat penting dalam kehidupan masyarakat pedesaan di Indonesia, karena bambu dikenal oleh masyarakat memiliki sifat-sifat yang baik untuk dimanfaatkan, antara lain memiliki batang yang kuat, lurus, rata, keras, mudah dibelah, mudah dibentuk dan mudah dikerjakan serta ringan sehingga mudah untuk didistribusikan. Selain itu bambu juga relatif murah dibandingkan dengan bahan bangunan lain karena banyak ditemukan di sekitar pemukiman pedesaan. Bambu menjadi tanaman serbaguna bagi masyarakat pedesaan.

Kabupaten Gianyar khususnya di Desa Belega, Kecamatan Blahbatuh, merupakan desa sentra penghasil barang kerajinan dari bambu. Kerajinan bambu merupakan ciri khas dari desa ini. Berbagai kerajinan dari bambu dihasilkan, diantaranya adalah kerajinan anyaman bambu, tas, souvenir dan furniture dari bambu. Jumlah pengrajin yang masih bertahan sampai saat ini tercatat 35 orang pengrajin (data di kantor Kepala Desa Belega), padahal pada tahun 1990 silam pengerajin yang ada di Desa Belega tercatat sebanyak 350 pengrajin. Pada tahun 1980 sampai dengan tahun 2000 tersebut hampir di setiap rumah membuat kerajinan bambu, (Perbekel Desa Belega/Trisna Jaya), oleh karena itu desa tersebut dikenal dengan nama Desa Bambu. Namun sejak tahun 2002 (pasca bom Bali) terjadi penurunan pengrajin dan yang tersisa hanya $10 \%$.

Bapak I Nyoman Sudiarta adalah salah satu pengrajin bambu. Usaha yang sudah ditekuni dari tahun 2000 ini berlokasi di Desa Belega, Blahbatuh Gianyar yang berjarak -/+ $20 \mathrm{~km}$ dari Kota Denpasar. Usaha tersebut merupakan usaha warisan dari orang tuanya dimana pada awalnya hanya membuat set kursi yang sederhana saja. Namun kemudian dikembangkan oleh Bapak I Nyoman Sudiarta dengan membuat produk yang lebih beragam lagi. Beliau adalah pengrajin barang kerajinan dari bambu dengan spesifikasi produk adalah furniture seperti set kursi berbagai bentuk, roomdivider (sekat ruangan), hanger dan bale bambu. Produk yang dihasilkan dipasarkan untuk kebutuhan masyarakat lokal dan wisatawan. Produk yang dihasilkan juga banyak diminati untuk keperluan furniture di hotelhotel dan villa. Bahan baku yang digunakan merupakan bahan baku ramah lingkungan yang di peroleh langsung dari petani yang berada di desa sekitar hingga pulau Jawa.

Produk dibuat berdasarkan pesanan dari pelanggan yang kebanyakan adalah hotel maupun villa yang berlokasi di Ubud, Kuta, Karangasem sampai Singaraja dan pesanan dari toko-toko kerajinan (art shop) yang berlokasi di Ubud, Tegalalang dan Batuan. Produk yang dibuat memiliki ukuran dan harga yang berbeda. Satu set kursi yang terdiri dari satu kursi panjang, dua kursi kecil dan satu meja dijual dengan harga Rp 2,5 juta sampai dengan $\operatorname{Rp} 4,5$ juta tergantung dari jenis bambu yang digunakan. Hanger dijual dengan harga $\mathrm{Rp} 100.000$ hingga Rp 150.000, roomdivider (sekat ruangan) dijual dengan harga Rp 500.000 hingga $\mathrm{Rp}$ 1 juta. Rata-rata omset yang diperoleh adalah Rp 20 juta sampai dengan 25 juta per bulan.

Berdasarkan observasi yang telah dilakukan terhadap usaha yang dikelola oleh Bapak I Nyoman Sudiarta tersebut, demi keberlanjutan dan eksistensinya sangat layak untuk 
mendapatkan pembinaan dan bantuan sehingga dapat meningkatkan kapasitas dan kualitas produk yang terkait dengan pelestarian produk unggulan desa Blega, Blahbatuh, Gianyar, pembinaan dan pembenahan manajemen, pemasaran dan aspek lainnya yang saling terkait.

Berdasarkan hasil observasi pada mitra, terdapat beberapa permasalahan yang menjadi kendala meliputi: 1) Belum memiliki pembukuan untuk menghitung laba rugi, harga pokok produksi dan pencatatan asset yang dimiliki, 2) Peralatan yang dimiliki masih sederhana seperti gergaji, alat memasang paku, dan beberapa yang sudah habis umur ekonomisnya sehingga sering mengalami kerusakan seperti bor besar, bor kecil, dan alat-alat pahat, 3) Kurangnya promosi dalam memasarkan produknya. Pemasaran dilakukan hanya mengandalkan pesanan dari pelanggan. Belum memiliki katalog produk sehingga pelanggan hanya mengetahui produk yang dipajang saja, 4) Kurang fasih berbahasa inggris sehingga kesulitan dalam berkomunikasi terutama kepada konsumen asing dalam memasarkan produknya.

Solusi yang ditawarkan untuk menyelesaikan permasalahan tersebut adalah: 1) Membantu membuat pencatatan keuangan, memberikan pendampingan dan konsultasi mengenai pembuatan sistem pembukuan yang meliputi buku harian, laba rugi, neraca, perhitungan harga pokok produksi, 2) Pendampingan dalam pembuatan katalog produk dan melakukan promosi melalui media elektronik sehingga mempermudah mitra dalam memasarkan produknya dan juga mempermudah dalam menerima pesanan dari pelanggannya, 3) Memberi pendampingan pelatihan dan pengajaran berbahasa inggris untuk memperlancar komunikasi terutama terhadap konsumen asing, 4) Pengadaan beberapa peralatan yang sudah tidak layak pakai agar dapat menunjang kelancaran proses produksi. Profil usaha mitra dapat dilihat pada Gambar 1.
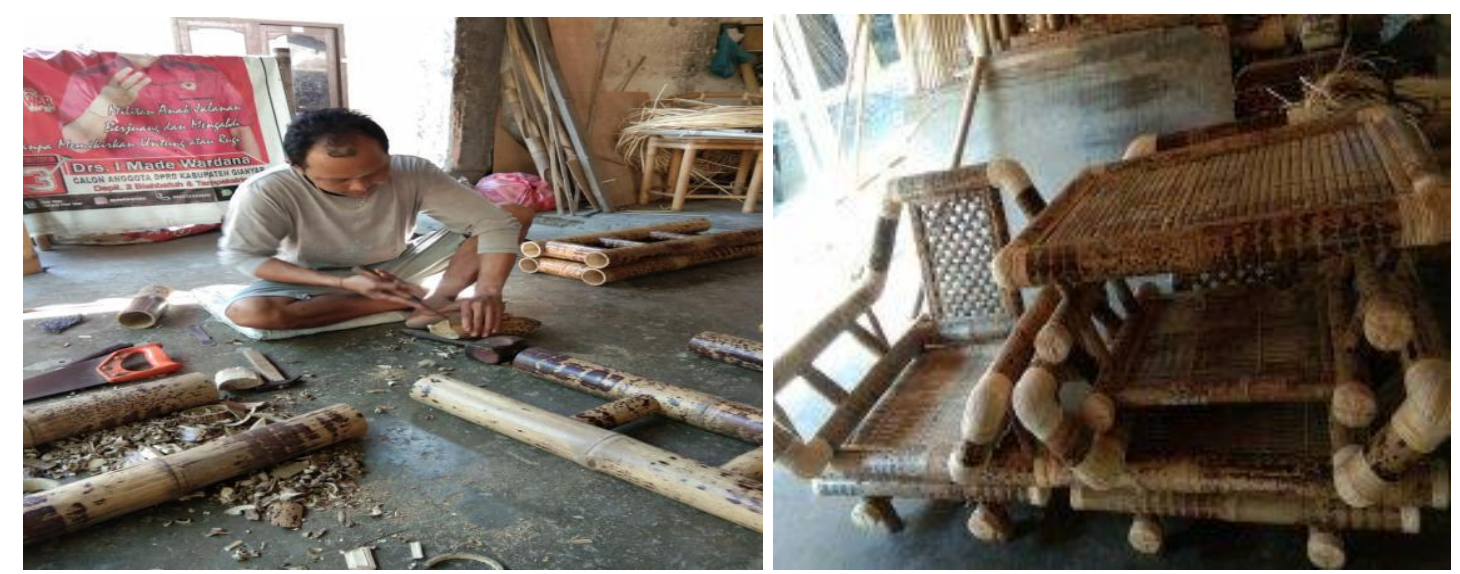

Gambar 1. Profil Usaha Mitra

Tujuan dari program pengabdian masyarakat ini adalah untuk mempertahankan Desa Belega sebagai Sentra pengrajin bambu, melalui pelatihan dan pendampingan. Dengan adanya pelatihan dan pendampingan diharapkan akan membatu mitra untuk meningkat kualitas produk yang nantinya akan berdampak terhadap omset.

\section{Materials and Methods}

Berdasarkan identifikasi permasalahan yang dihadapi mitra dan solusi yang ditawarkan, maka metode pelaksanaan kegiatan yang dilakukan adalah: 1) Pendampingan dalam pembuatan pembukuan dan laporan keuangan sederhana. Hal ini dilakukan untuk dapat mengetahui laba atau rugi yang diperoleh dari hasil usahanya dan untuk mengetahui berapa cost yang dikeluarkan untuk memproduksi suatu produk. Pendampingan dan pelatihan 
ini diharapkan dapat memberikan manfaat ekonomi di masa depan bagi pengembangan usaha mitra, 2) Pendampingan dalam pembuatan katalog produk dan melakukan promosi melalui media cetak maupun elektronik, 3) Pendampingan memberikan pelatihan dan pengajaran berbahasa inggris sederhana untuk memperlancar komunikasi terhadap konsumen asing, 4) Pengadaan beberapa peralatan yang sudah tidak layak pakai agar dapat menunjang kelancaran proses produksi

\section{Results and Discussion}

Capaian pelaksanaan kegiatan sesuai dengan yang diprioritaskan pada mitra, yaitu :

\section{Pengadaan Beberapa Peralatan}

Pembelian peralatan yang terdiri dari gergaji, alat bor (BOSCH GBM PROFESSIONAL), dan satu set peralatan pahat. Peralatan ini berguna untuk melakukan pergantian terhadap peralatan yang sudah dimiliki untuk melakukan proses produksi, namun sudah habis umur ekonomisnya yang menyebabkan proses produksi terganggu. Gambar serah terima peralatan kepada mitra di Desa Belega dapat dilihat pada Gambar 2.

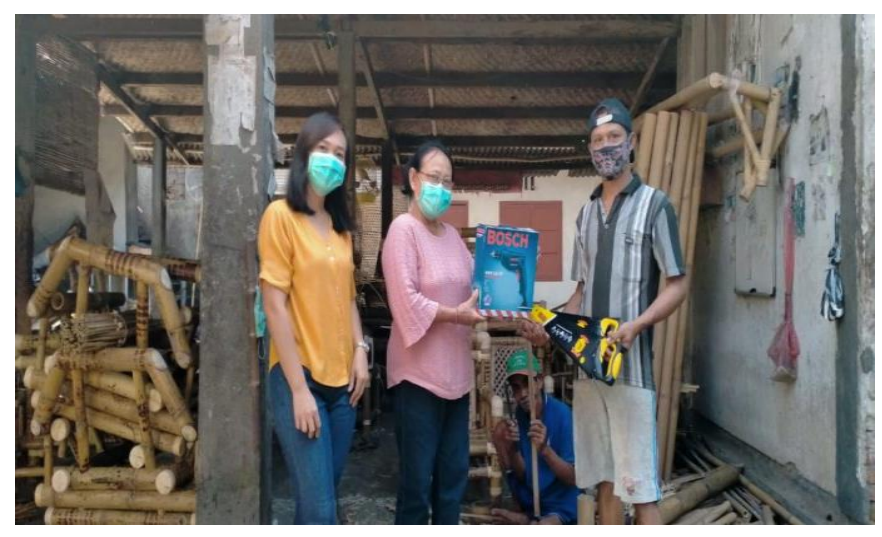

Gambar 2. Serah Terima Peralatan Produksi

\section{Pelatihan dan Pendampingan Pembuatan Pembukuan Sederhana}

Pelatihan dan pendampingan dalam membuat pembukuan dan laporan keuangan sederhana untuk memudahkan mitra dalam menentukan cost yang dikeluarkan, menentukan harga pokok produksi dan menghitung laba/ rugi. Mitra diajarkan pencatatan pembukuan manual agar mudah untuk dipahami. Kegiatan pelatihan dan pendampingan pembuatan pembukuan sederhana dapat dilihat pada Gambar 3.

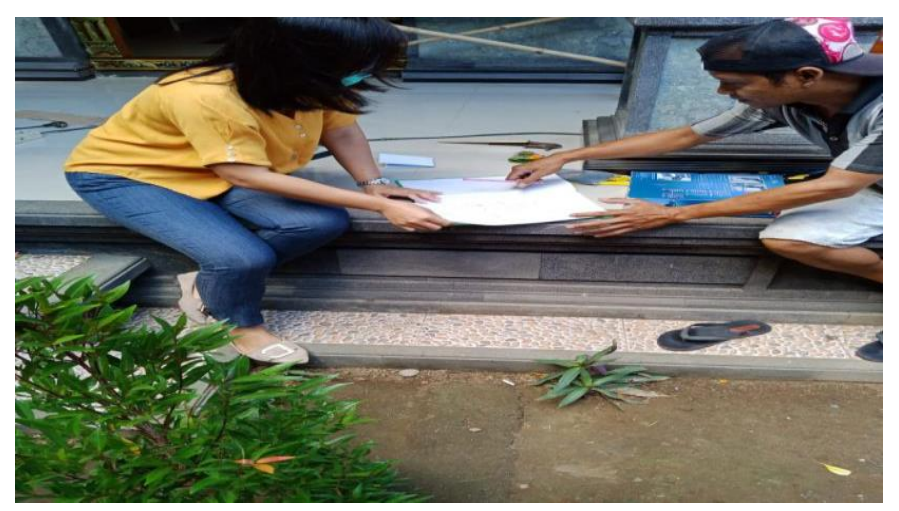

Gambar 3. Pelatihan dan Pendampingan Pembuatan Pembukuan Sederhana 
Pelatihan dan pendampingan pembukuan ini sangat bermanfaat bagi mitra. Dengan memahami pencatatan keuangan mitra jadi tahu berapa cost yang dikeluarkan dalam memproduksi barang dan mampu menentukan harga jual yang tepat sehingga memperoleh keuntungan sesuai yang diharapkan.

\section{Pelatihan dan Pendampingan Pemasaran Produk}

Pelatihan pemasaran yang dilakukan adalah membuat katalog produk. Katalog produk dibuat secara cetak dan online. Mitra juga diberikan pelatihan bahasa inggris sederhana agar dapat memperluas pangsa pasar. Pelatihan dan pendampingan pemasaran ini memberikan banyak manfaat bagi mitra. Dengan pelatihan dan pendampingan yang diberikan ini, usaha mitra jadi lebih dikenal, pansa pasarnya menjadi lebih luas dan kapasitas produksipun menjadi meningkat. Kegiatan pelatihan dan pendampingan pemasaran dapat dilihat pada Gambar 4.
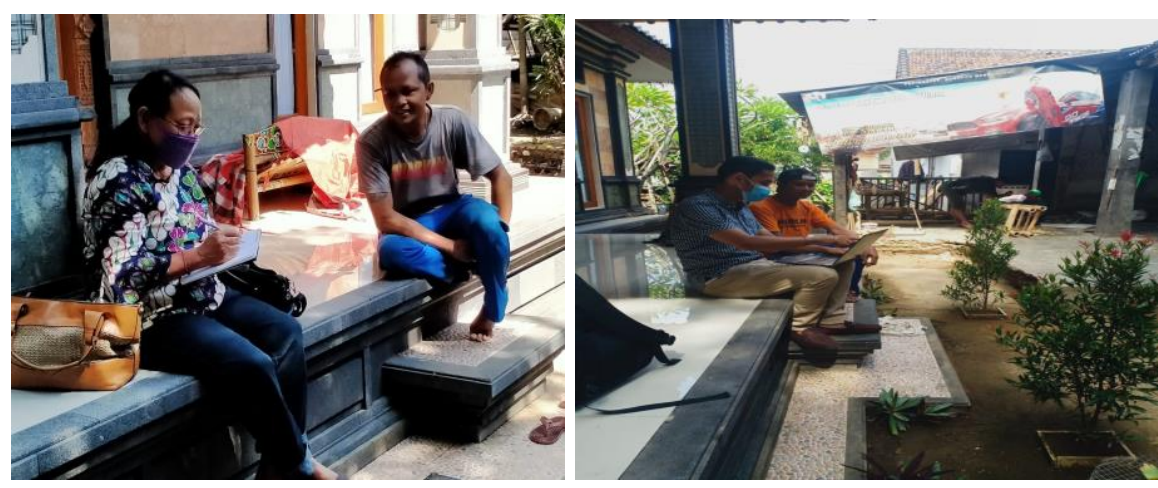

Gambar 4. Pelatihan dan Pendampingan Pemasaran

Pelaksanaan kegiatan pengabdian ini memberikan dampak positif bagi mitra. Dengan pelatihan dan pendampingan pembukuan sederhana serta pelatihan dan pendampingan sistem pemasaran dapat meningkatkan omset dan pendapatan mitra. Pengadaan peralatan untuk menggantikan beberapa peralatan yang rusak sangat membantu mitra dalam menunjang produksinya. Produksi menjadi lebih cepat dan kuantitas produksipun meningkat. Indikator capaian dapat ditampilkan dalam Tabel 1 berikut.

Tabel 1. Indikator Capaian Kegiatan

\begin{tabular}{lc}
\hline \multicolumn{1}{c}{ Keterangan } & Progress \\
\hline Peningkatan Aset & $+/-20 \%$ \\
Peningkatan omset / bulan & $+/-20 \%$ \\
Peningkatan produksi / bulan & $+/-20 \%$ \\
Penigkatan tenaga kerja & $+/-30 \%$ \\
\hline
\end{tabular}

Berdasarkan hasil kegiatan pelaksanaan program ini mampu meningkatkan aset, omset, kuantitas produksi serta jumlah tenaga kerja yang digunakan. Hal ini tidak terlepas dari proses pelatihan dan bimbingan yang diberikan. Dengan adanya pelatihan dan bimbingan akan sangat membantu mitra lebih mengembangkan kualitas produk yang dihasilkan. Dengan pembimbing dan pelatihan tentang kendala-kendala yang dihadapi oleh mitra akan membuat mitra tahu apa yang harus dilakukan. Pelatihan dilakukan dengan tujuan memperdalam pemahaman personil terhadap proses produksi dan parameter kritis dari proses, menyediakan latihan untuk penanganan atas masalah yang terjadi. Hubungan antara 
pelatihan dan pendapatan sangat kuat dan positif, semakin baik pelatihan maka pendapatan akan semakin meningkat (Harini et al., 2015). Pelatihan dilakukan untuk membentuk personil yang terkualifikasi dan memiliki pemahaman akan peran dan tanggung jawabnya (Ratnadevi \& Musfiroh, 2018; Susanto et al., 2018). Jadi, pelatihan adalah serangkaian aktivitas yang dirancang untuk meningkatkan keahlian-keahlian, pengetahuan, pengalaman ataupun perubahan sikap seorang individu.

\section{Conclusion}

Berdasarkan uraian kegiatan yang sudah dilakukan dalam pengabdian program kemitraan masyarakat terhadap usaha kerajinan bambu bapak I Nyoman Sudiarta, dapat disimpulkan bahwa mitra telah mendapatkan pelatihan dan pendampingan pembuatan pembukuan sederhana, telah mendapatkan pelatihan dan pendampingan sistem pemasaran serta telah menerima bantuan pengadaan beberapa peralatan. Pelaksanaan program ini mampu meningkatkan aset, omset, kuantitas produksi serta jumlah tenaga kerja yang digunakan.

\section{References}

Adhany, I., \& Siregar, R. A. (2020). Peningkatan Ketrampilan Dan Pengetahuan Kelompok Tani Pemuda Tani Dalam Pembuatan Keranjang Bambu Di Desa Aornakan 1, Kabupaten Pakpak Bharat, Sumatera Utara. Jurnal Argohita, 5(1), 76-81. https://doi.org/10.31604/jap.v5i1.1730

Arhamsyah, A. (2009). Pengolahan Bambu Dan Pemanfaatannya Dalam Usaha Pengembangan Industri Kecil Menengah Dan Kerajinan. Jurnal Riset Industri Hasil Hutan, 1(2), 30. https://doi.org/10.24111/jrihh.v1i2.889

Arsad, E. (2015). Teknologi Pengolahan Dan Manfaat Bambu. Jurnal Riset Industri Hasil Hutan, 7(1), 45. https://doi.org/10.24111/jrihh.v7i1.856

Harini, S., Pertiwi, S. R., \& Rochman, N. (2015). Peningkatan Kualitas SDM Melalui Pelatihan dan Pengaruhnya Terhadap Peningkatan Pendapatan. Media Pengabdian Kepada Masyarakat Qardhul Hasan, 1(April), 49-65.

Linda, F., Linda, R., \& Rafdinal. (2017). Rotan dan Bambu yang Bernilai Ekonomis oleh Masyarakat Suku Dayak Kanayatn di Kecamatan Sengah Temila, Pemanfaatan. Protobiont, $6(3)$ 233-239. https://jurnal.untan.ac.id/index.php/jprb/article/view/22484

Putro, D. S., \& Murningsih, J. (2014). Keanekaragaman jenis dan pemanfaatan bambu di Desa Lopait Kabupaten Semarang Jawa Tengah. Jurnal Biologi, 3(2), 71-79. https://ejournal3.undip.ac.id/index.php/biologi/article/download/19446/18445

Rahmawati, R., Baharuddin, B., \& Putranto, B. (2019). Potensi dan pemanfaatan bambu tali (gigantochloa apus) di desa leu kecamatan bolo Kabupaten Bima. Perennial, 15(1), 27. https://doi.org/10.24259/perennial.v15i1.6790

Raka, I. D. N., Wiswasta, I. G. N. A., \& Budiasa, I. M. (2011). Pelestarian tanaman bambu sebagai upaya rehabilitasi lahan dan konservasi tanah di daerah sekitar mata air pada lahan marginal di Bali Timur. Jurnal Pertanian Berbasis Keseimbangan Ekosistem, 1(1), 11-21. https://media.neliti.com/media/publications/90074-ID-pelestariantanaman-bambu-sebagai-upaya.pdf

Ratnadevi, T., \& Musfiroh, I. (2018). Peran Pelatihan Personil Dalam Menjaga Mutu Produk Di Industri Farmasi. Farmaka, 15(3), 47-56. 
http://jurnal.unpad.ac.id/farmaka/article/view/15161

Saputra, B. E., Anam, M. K., Khasanah, M., Maharani, A., Nindita, V., Pendahuluan, A., S, B. E., Muhammad, K. A., Miftahul, K., \& Nindita, V. (2019). PKM ILAMESIA : Inovasi Lampu Hias Alam Indonesia. Jurnal DIANMAS, 8(April), 67-74. http://jurnaldianmas.org/index.php/Dianmas/article/download/153/113

Sulistiono, Karyaningsih, I., \& Nugraha, A. (2016). Keanekaragaman jenis bambu dan pemanfaatannya di kawasan hutan Gunung Tilu Desa Jabranti Kecamatan Karangkencana Kabupaten Kuningan. Jurnal Riset Industri Hasil Hutan, 15(1), 45. https://www.journal.uniku.ac.id/index.php/wanaraksa/article/viewFile/1062/752

Susanto, M. R., Setiawati, S. W., \& Hartanto, A. D. (2018). Revitalisasi mutu produk ekspor melalui pendampingan inovasi desain produk dan hki patung terrazzo di bantul yogyakarta 1. Jurnal Dharma Bakti, 1(1), 1-12. https://ejournal.akprind.ac.id/index.php/dharma/article/download/289/198

Tang, M., Malik, A., \& Hapid., A. (2019). Pemanfaatan Hasil Hutan Bukan Kayu (HHBK) Bambu oleh Masyarakat Terasing (Suku Lauje)Di Desa Anggasan Kecamatan Dondo Kabupaten Tolitoli. Jurnal Warta Rimba, 7(2015), 72-77. http://jurnaldianmas.org/index.php/Dianmas/article/download/153/113 